\title{
Yellow fever mosquito Aedes aegypti (Linnaeus) (Insecta: Diptera: Culicidae) ${ }^{1}$
}

Catherine Zettel and Phillip Kaufman ${ }^{2}$

\section{Introduction}

The yellow fever mosquito, Aedes aegypti (Linnaeus), has been a nuisance species in the United States for centuries. Originating in Africa, it was most likely brought to the new world on ships used for European exploration and colonization (Nelson 1986). As the common name suggests, Ae. aegypti is the primary vector of yellow fever, a disease that is prevalent in tropical South America and Africa, and often emerges in temperate regions during summer months. During the Spanish-American War, U.S. troops suffered more casualties from yellow fever transmitted by Ae. aegypti than from enemy fire (Tabachnick 1991).

The yellow fever mosquito was a common vector in Florida until the invasion of the Asian tiger mosquito, Aedes albopictus (Skuse). Since the introduction of the Asian tiger mosquito in 1985, by way of Texas, the population of Ae. aegypti in Florida has declined dramatically, but still thrives in urban areas of South Florida. Aedes albopictus larvae out-compete Ae. aegypti larvae for food, and develop at a faster rate (Barrera 1996). Some research also 
areas, in close contact with people making them an exceptionally successful vector. Aedes aegypti are extremely common in areas lacking piped water systems, and depend greatly on stored water for breeding sites. Male and female adults feed on nectar of plants; however, females bloodfeed primarily on humans in order to produce eggs, and are active in the daytime. Eggs have the ability to survive desiccation for long periods of time, allowing eggs to be easily spread to new locations.

For additional information on mosquitoes, see http://edis.ifas.ufl.edu/IN652.

\section{Synonymy}

Culex aegypti Linnaeus 1762

Culex excitans Walker 1848

Culex taeniatus Weidemann 1828

Aedes aegypti Mattingly, Stone, and Knight 1962

From the Integrated Taxonomic Information System and International Commission on Zoological Nomenclature.

\section{Distribution}

The yellow fever mosquito has a cosmo-tropical distribution annually, and spreads to more temperate regions during the summer months. Originating in Africa, Ae. aegypti is now present globally in tropical and sub-tropical regions.

In the early $1900 \mathrm{~s}$, Ae. aegypti distribution extended from the southern United States down to Argentina. The mid-1900s saw the development of a fairly successful Ae. aegypti eradication program throughout its range in North and South America as a method to control yellow fever through education, adult mosquito control, and manipulation of container breeding sites. Though initially successful, Ae. aegypti has reestablished in most of the pre-eradication range due to lack of commitment and financial backing necessary to maintain the eradication program (Nelson 1986). The program is no longer operational today.

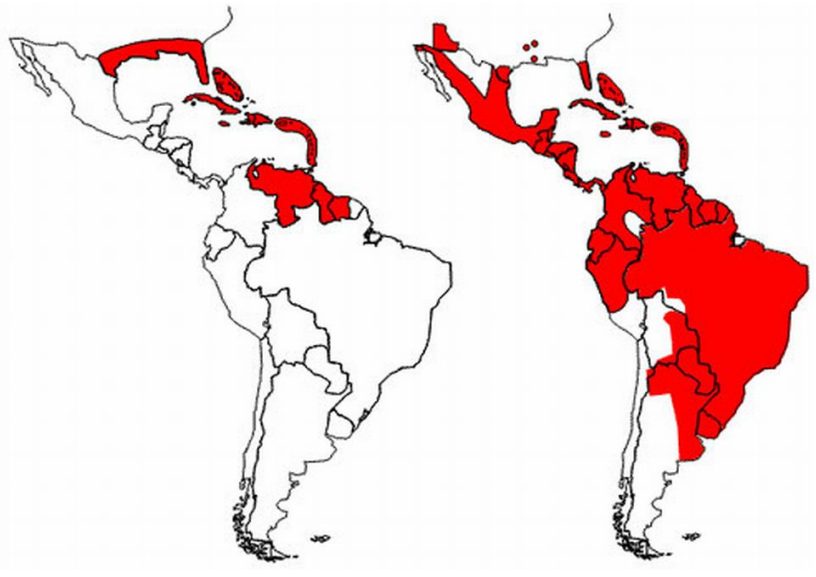

Figure 2. Reinfestation by the yellow fever mosquito, Aedes aegypti (Linnaeus), in the Americas, as of 2002. Left image shows reduction of range resulting from the eradication programs beginning in the mid-1990s. Right image shows reinfestation resulting from the end of the eradication programs. Credits: Illustration by: $\mathrm{PAHO} / \mathrm{WHO}$ 2002

In the United States, Ae. aegypti is found in 23 states, including the southeastern U.S., up the east coast to New York, and west to Indiana and Kentucky (Darsie and Ward 2005) although in some areas Ae. aegypti populations are decreasing due to competition with Ae. albopictus. Aedes aegypti is still a common mosquito in urban areas of southern Florida, and in cities along the Gulf coast of Texas and Louisiana.

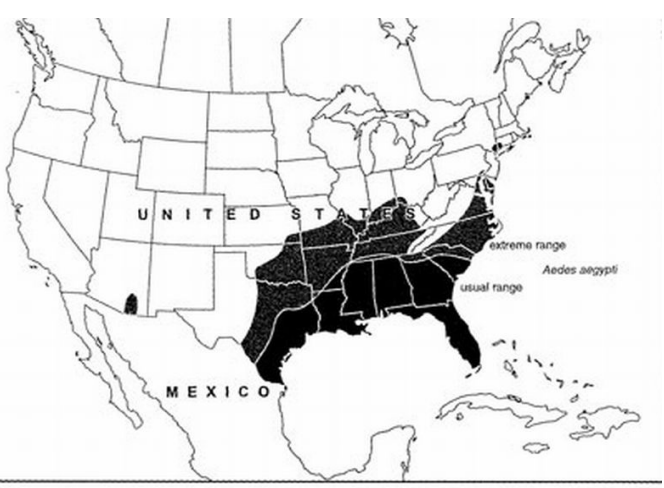

Hote 9 B. Distribution of Aedes aegypti-USA: Al, AR, DC, FL, GA, IL, IN, KS, KY, LA, MS, MO, NC, OK, SC, TN, TX, VA 146), MO (716), NY (48), NJ (232), AZ (490), OH (Berry \& Parsons, pers. comm. 1978); Map modified after Morlond \& linker (500): Tax. 42, 431 .

Figure 3. Distribution of the yellow fever mosquito, Aedes aegypti (Linnaeus), in the United States as of 2005. Credits: Darsie RF, Ward RA

\section{Description}

The adult yellow fever mosquito is a small to medium-sized mosquito, approximately 4 to 7 millimeters. To the unaided eye, adult yellow fever mosquitoes resemble the Asian tiger mosquito with a 
slight difference in size and thorax patterns. Aedes aegypti adults have white scales on the dorsal (top) surface of the thorax that form the shape of a violin or lyre, while adult Ae. albopictus have a white stripe down the middle of the top of the thorax. Each tarsal segment of the hind legs possesses white basal bands, forming what appear to be stripes. The abdomen is generally dark brown to black, but also may possess white scales (Carpenter and LaCasse 1955).

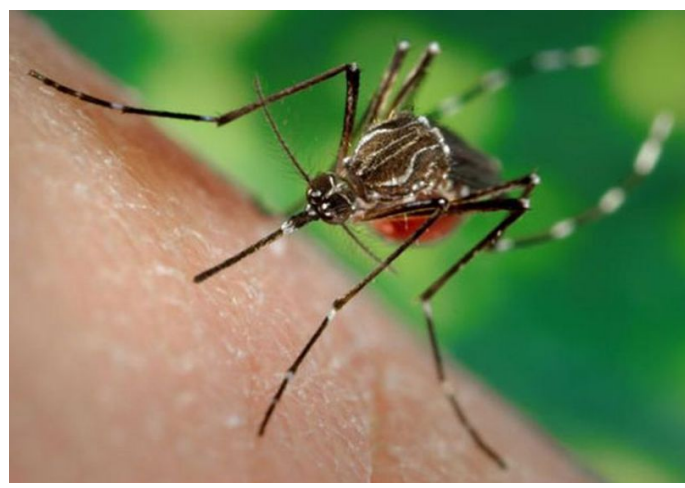

Figure 4. Adult yellow fever mosquito, Aedes aegypti (Linnaeus), showing the white "lyre" shape on the dorsal side of the thorax. Credits: Paul Howell and Frank Hadley Collins, Center for Disease Control Public Health Image Library

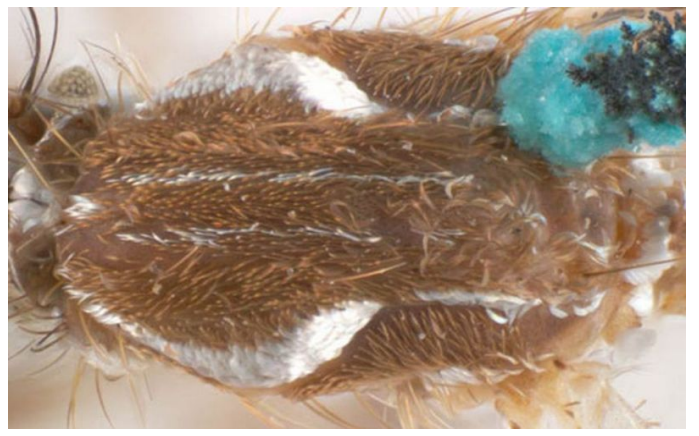

Figure 5. Close-up of the "lyre" on an adult yellow fever mosquito, Aedes aegypti (Linnaeus). Credits: Simon Hinkley and Ken Walker, Pest and Diseases Image Library

Females are larger than males, and can be distinguished by small palps tipped with silver or white scales. Males have plumose antennae, whereas females have sparse short hairs. When viewed under a microscope, male mouthparts are modified for nectar feeding, and female mouthparts are modified for blood feeding. The proboscis of both sexes is dark, and the clypeus (segment above the proboscis) has two clusters of white scales. The tip of the abdomen comes to a point, which is characteristic of all Aedes species (Cutwa-Francis and O'Meara 2007).

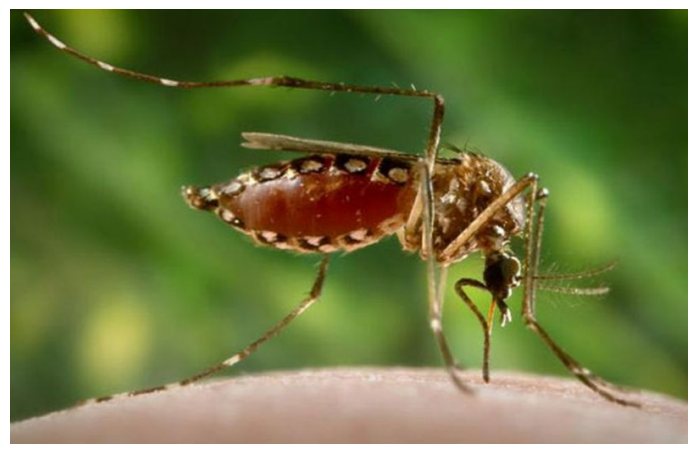

Figure 6. An adult female yellow fever mosquito, Aedes aegypti (Linnaeus), in the process of acquiring a blood meal from its human host, after having penetrated the skin surface with the sharply-pointed "fascicle." Note that her abdomen has become distended as her stomach is filling with her blood meal, and how the proboscis' labial sheath is in its retracted, pulled back configuration, exposing the inserted, sharp fascicle, which has turned red, as the blood is passing up the straw-like apparatus. Credits: James Gathany, Center for Disease Control Public Health Image Library

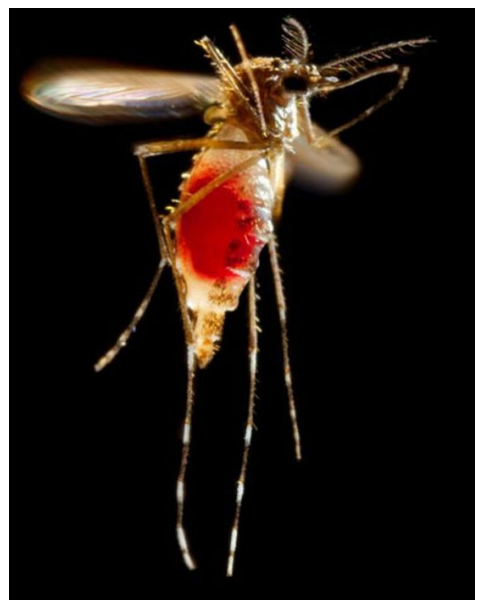

Figure 7. An adult female yellow fever mosquito, Aedes aegypti (Linnaeus), with a newly-obtained fiery red blood meal visible through her now transparent abdomen. The now heavy female mosquito takes flight as she leaves her host's skin surface. After having filled with blood, the abdomen became distended, stretching the exterior exoskeletal surface, causing it to become transparent, and allowed the collecting blood to become visible as an enlarging intra-abdominal red mass. Note also the clearly defined head, mouth parts and legs. Credits: Frank Hadley Collins, Center for Disease Control Public Health Image Library

For a pictorial key of Florida mosquitoes, including Ae. aegypti, see the Florida Medical Entomology Laboratory's Identification Guide to Common Mosquitoes of Florida website at: http://fmel.ifas.ufl.edu/Key/index.htm. 


\section{Life Cycle}

Adults: Aedes aegypti is a holometabolous insect, meaning that it goes through a complete metamorphosis with an egg, larva, pupa, and adult stage. The adult life span can range from two weeks to a month depending on environmental conditions (Maricopa, 2006). Aedes aegypti comes in three polytypic forms: domestic, sylvan, and peridomestic. The domestic form breeds in urban habitat, often around or inside houses. The sylvan form is a more rural form, and breeds in tree holes, generally in forests, and the peridomestic form thrives in environmentally modified areas such as coconut groves and farms (Tabachnick et al. 1978).

Eggs: After taking a complete blood meal, females produce on average 100 to 200 eggs per batch; however, the number of eggs produced is dependent on the size of the bloodmeal. Females can produce up to five batches of eggs during a lifetime. A smaller bloodmeal produces fewer eggs (Nelson 1986). Eggs are laid on damp surfaces in areas likely to temporarily flood, such as tree holes and man-made containers, and are laid singly, rather than in a mass. Not all the eggs are laid at once, but can be spread out over hours or days, depending on the availability of suitable substrates (Clements 1999). Most often, eggs will be placed at varying distances above the water line, and a female will not lay the entire clutch at a single site, but rather spread out the eggs over two or more sites (Foster and Walker 2002).

Eggs of Ae. aegypti are long, smooth, ovoid shaped, and approximately one millimeter long. When first laid, eggs appear white but within minutes turn a shiny black. In warm climates, such as the tropics, eggs may develop in as little as two days, whereas in cooler temperate climates, development can take up to a week (Foster and Walker 2002). Aedes aegypti eggs can survive desiccation for months and hatch once submerged in water, making the control of Ae. aegypti difficult (Nelson 1984).

Larvae: Mosquito larvae are often called "wrigglers" or "wigglers," because they appear to wiggle sporadically in the water when disturbed. Larval Ae. aegypti breathe oxygen through a posteriorly located siphon, which is held above the

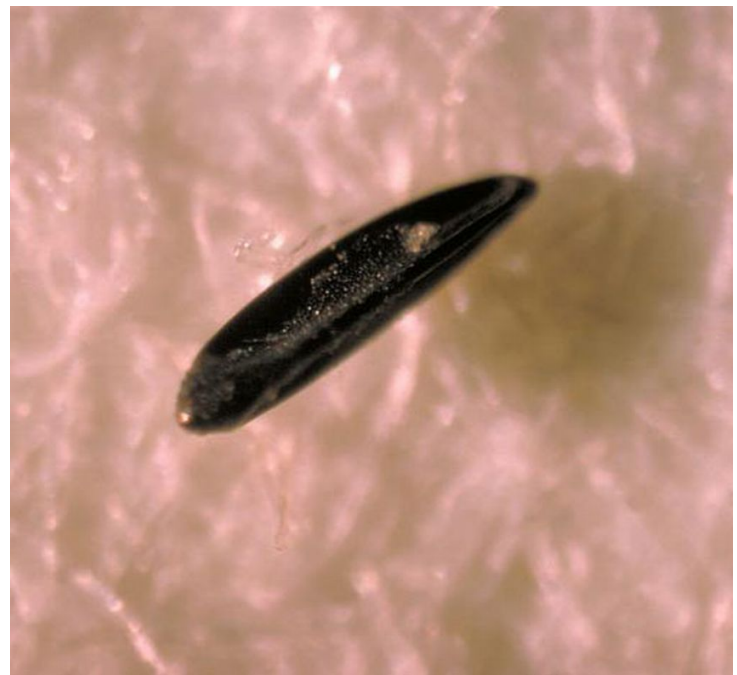

Figure 8. Egg of the yellow fever mosquito, Aedes aegypti (Linnaeus). Credits: Center for Disease Control Public Health Image Library

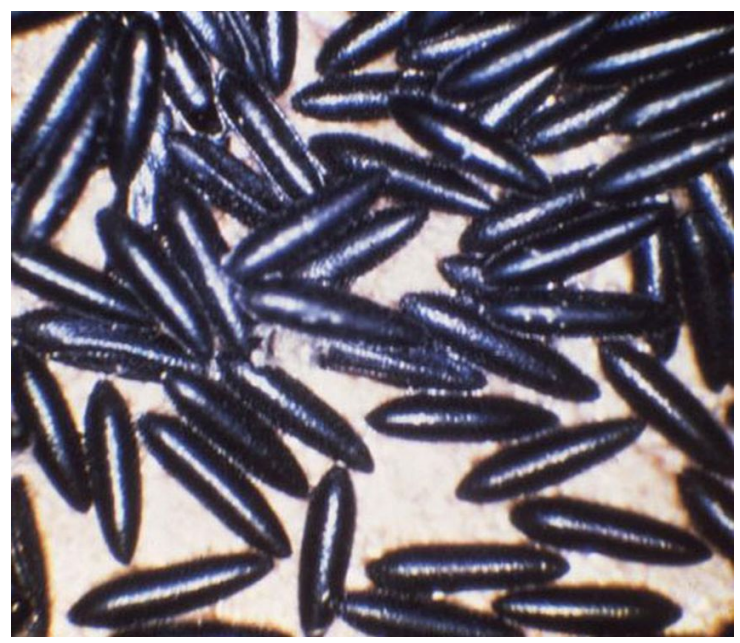

Figure 9. Eggs of the yellow fever mosquito, Aedes aegypti (Linnaeus). Credits: Center for Disease Control Public Health Image Library

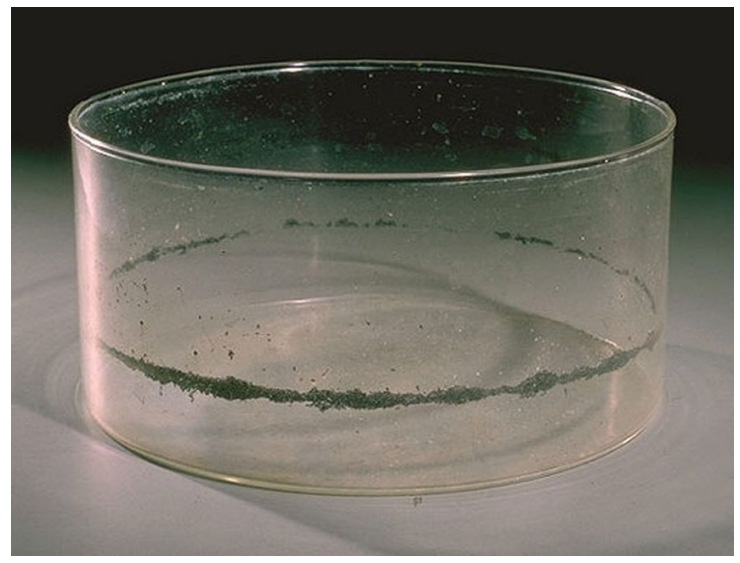

Figure 10. Eggs of the yellow fever mosquito, Aedes aegypti (Linnaeus), in glass container. Credits: Center for Disease Control Public Health Image Library 
water surface while the rest of the body hangs vertically. Most Aedes larvae can be distinguished from other genera by the unaided eye by their short siphon (Nelson 1986).

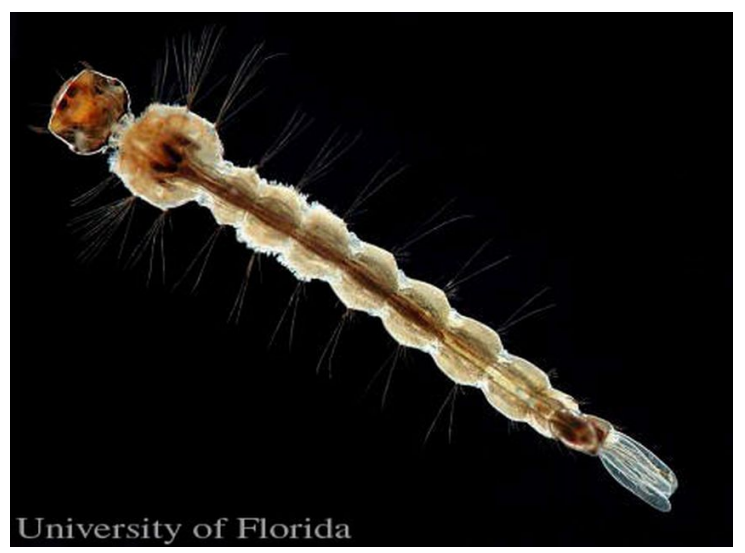

Figure 11. Fourth instar larva of the yellow fever mosquito, Aedes aegypti (Linnaeus). Credits: Michele Cutwa-Francis, University of Florida

Larvae feed on organic particulate matter in the water, such as algae and other microscopic organisms. Most of the larval stage of Ae. aegypti is spent at the water's surface, although they will swim to the bottom of the container if disturbed or when feeding (Nelson 1984).

Larvae are often found around the home in puddles, tires, or within any object holding water. Larval development is temperature dependent. The larvae pass through four instars, spending a short amount of time in the first three, and up to three days in the fourth instar. Fourth instar larvae are approximately eight millimeters long. Males develop faster than females, so males generally pupate earlier. If temperatures are cool, Ae. aegypti can remain in the larval stage for months so long as the water supply is sufficient (Foster and Walker 2002).

Pupae: After the fourth instar, Ae. aegypti enter the pupal stage. Mosquito pupae are different from many other holometabolous insects in that the pupae are mobile and respond to stimuli. Pupae, also called "tumblers," do not feed and take approximately two days to develop. Adults emerge by ingesting air to expand the abdomen thus splitting open the pupal case and emerge head first.

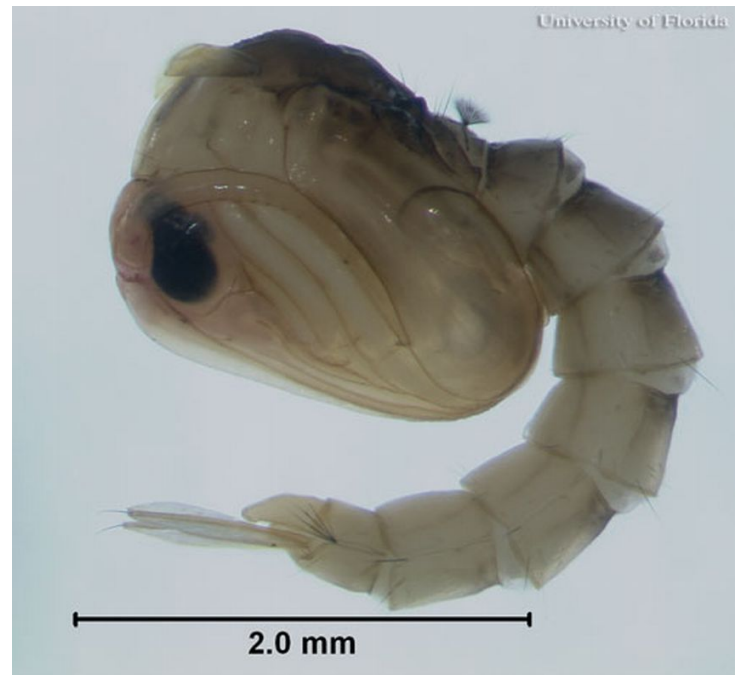

Figure 12. Pupa of the yellow fever mosquito, Aedes aegypti (Linnaeus). Credits: C.M. Zettel, University of Florida

\section{Medical Importance}

Aedes aegypti are pests. Bites cause minor localized itching and irritation to the skin, and can make an outdoor adventure very unpleasant. Most bites are not medically significant, but can be annoying. While many mosquitoes bite at night, dawn or dusk, Ae. aegypti readily bite during the day and indoors as well as outdoors. As the name suggests, the yellow fever mosquito is the primary vector of the yellow fever virus.

Yellow fever epidemics still occur frequently in the tropics, and can occur in temperate regions during summer months, although it is not the major threat it once was. Today, there is a very successful vaccine for yellow fever, which has contributed to the decline in cases in the United States. In 1951, Max Theiler won a Nobel Prize for his vaccine, which is the only Nobel Prize given for a vaccine to date (Norrby 2007). For more information on yellow fever, see http://edis.ifas.ufl.edu/IN659.

While the United States rarely experiences yellow fever cases, the most recent concern to the United States and Florida is the transmission of dengue virus. Dengue is also known as "break-bone fever" for the excruciating pain victims feel. Dengue is a dangerous disease due to four different serotypes: DEN-1, DEN-2, DEN-3, and DEN-4 (Rey 2007). Although a person can obtain immunity to one serotype, they are still susceptible to the others. The 
most deadly is dengue hemorrhagic fever (DHF), which is often fatal. In 1981, Cuba experienced a major DHF outbreak, killing 159 people (Nelson 1984). Though outbreaks in the United States are still rare, Mexico is experiencing major dengue outbreaks, and its close proximation could lead to outbreaks in the United States. Like yellow fever, dengue fever is caused by a flavivirus (attacks the liver), and can only be transmitted by female mosquitoes. To more information on dengue fever, see http://edis.ifas.ufl.edu/IN699.

Aedes aegypti are vectors of other important viruses of concern to North America, such as chikungunya virus. Although chikungunya is not endemic in North America, like dengue, the number of cases is steadily increasing and this virus could become a major threat to public health in the United States. Most cases documented in the United States are associated with international travel, but with the spread and resurgence of the yellow fever mosquito and Asian tiger mosquito in the Americas, chikungunya is a very real threat (Centers for Disease Control, 2007). For more information on chikungunya, see http://fmel.ifas.ufl.edu/fmbuzz/wtchicun.htm and http://edis.ifas.ufl.edu/IN696.

\section{Management}

Aedes aegypti control first began in the early 1900s, when officials in South America began treating water tanks with insecticide in order to reduce the number of adult mosquitoes. After initial success, efforts were decreased on the assumption that the populations of yellow fever mosquitoes would not return. However, within a decade, Ae. aegypti populations returned to levels seen before the water treatments had occurred and urban yellow fever was again rampant (Severo 1959).

In 1947, the Pan American Health Organization implemented an eradication program for Ae. aegypti in hopes of eliminating yellow fever outbreaks in the Western hemisphere. As of 1965, 19 countries had completed the program and were declared Ae. aegypti free (Soper 1965). After the eradication program ended, low doses of malathion were used for control, but Ae. aegypi rapidly developed resistance to the

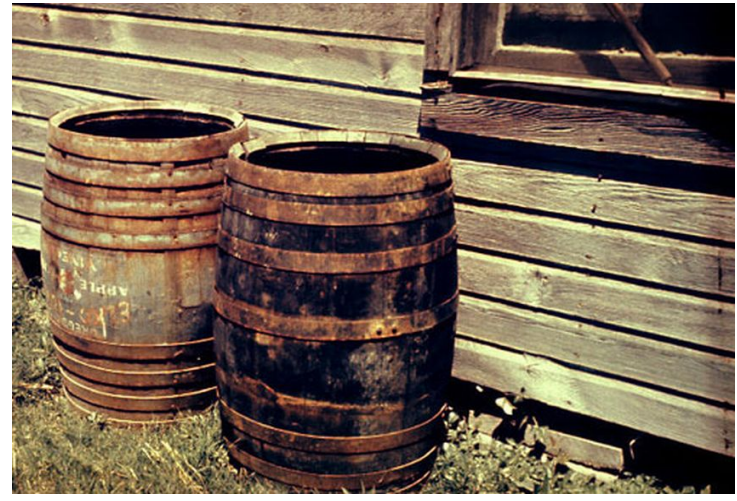

Figure 13. Rain barrels around the home are prime breeding locations for the yellow fever mosquito, Aedes aegypti (Linnaeus). Credits: Center for Disease Control Public Health Image Library

pesticide (Gubler 1989). In 1965, Florida initiated an Ae. agypti eradication program through the 67 county health departments and the U.S. Public Health Service to prevent yellow fever and dengue outbreaks (Florida State Board of Health 1965).

Unfortunately, Ae. aegypti has reestablished itself throughout the Americas and has expanded its range in the United States. No eradication program is currently operational, but there are several steps individuals can take to reduce localized mosquito numbers. Because Ae. aegypti are container-inhabiting mosquitoes, one of the most successful and cost-effective methods to reducing populations is by preventing containers around the home from collecting water.

By turning over empty flowerpots, properly maintaining swimming pools, and removing unused tires, you can greatly reduce the number of places mosquitoes have to lay eggs. Aerate birdbaths and make sure gutters are free of blockages. Clean pet bowls everyday and always empty overflow dishes for potted plants.

For personal protection from bites, apply an insect repellant, and wear long pants and long sleeves when outside. For more information on mosquito management, please visit the Florida Medical Entomology Laboratory mosquito management website

at:

http://mosquito.ifas.ufl.edu/ Mosquito_Management.htm. 


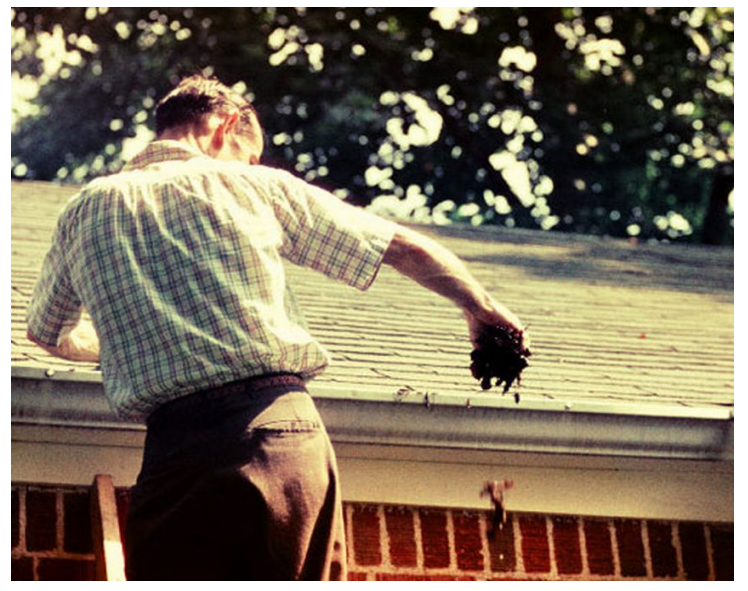

Figure 14. Organic matter left in gutters allows water to collect and mosquitoes to breed. Keep gutters clean so water can flow out. Credits: Center for Disease Control Public Health Image Library

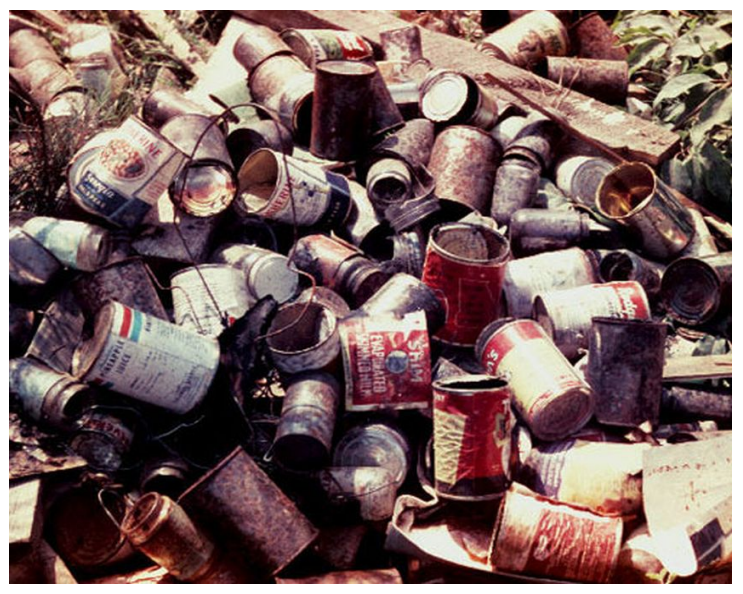

Figure 15. Mosquitoes can breed in tin cans in open dumps or around the yard. Credits: Center for Disease Control Public Health Image Library

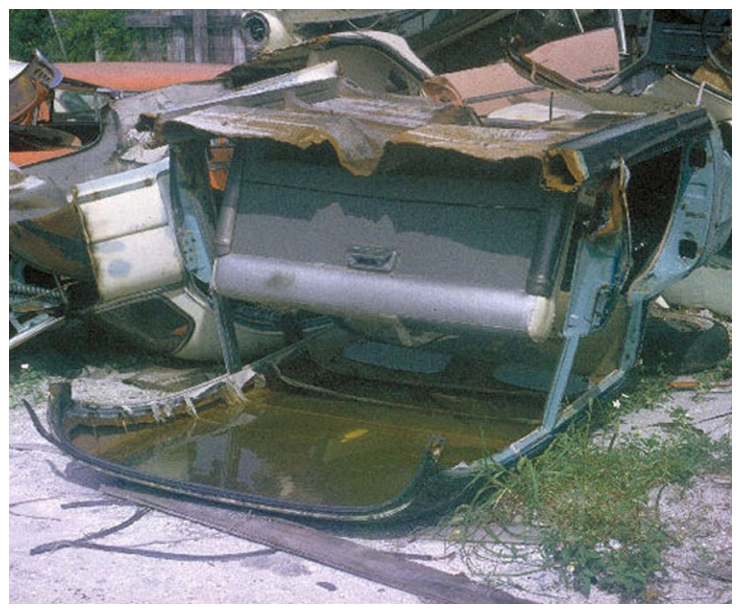

Figure 16. Domestic mosquitoes can breed in junk yards, open dumps or anywhere stationary water collects. Credits: Center for Disease Control Public Health Image Library
For information regarding mosquito management devices for the home, see http://edis.ifas.ufl.edu/IN171.

\section{Selected References}

Arbovirus Summary Archives. (2008). Repellents, Traps, Virus Information, Maps, etc. Pest Alert.

http://entomology.ifas.ufl.edu/pestalert/arbovirus/ arbovirus.htm (14 May 2008).

Barrera R. 1996. Competition and resistance to starvation in larvae of container-inhabiting Aedes mosquitoes. Ecological Entomology. 21: 117-127.

Carpenter SJ, LaCasse WJ. 1955. Mosquitoes of North America (North of Mexico). University of California Press, Berkeley, CA. 360 pp.

Centers for Disease Control. (2007). Chikungunya fever fact sheet. Division for Vector-borne Infectious Diseases: Centers for Disease Control.

http://www.cdc.gov/ncidod/dvbid/chikungunya/ (13 May 2008).

Clements AN. 1999. The Biology of Mosquitoes, Vol. II. Egg laying. Cabi, Wallingford.

Cutwa-Francis MM, O'Meara GF. (2007). An Identification Guide to the Common Mosquitoes of Florida. Florida Medical Entomology Laboratory. http://mosquito.ifas.ufl.edu (13 May 2008).

Darsie, RF, Ward, RA. 2005. Identification and Geographical Distribution of the Mosquitoes of North America, North of Mexico. University of Florida Press, Gainesville, FL. 300 pp.

Fasulo TR, Dame DA. (2002). Mosquitoes 1 and Mosquitoes 2. Bug Tutorials. University of Florida/IFAS. CD-ROM. SW 160.

Fasulo TR, Kern W, Koehler PG, Short DE. (2005). Pests In and Around the Home. Version 2.0. University of Florida/IFAS. CD-ROM. SW 126.

Florida Medical Entomology Laboratory. (2007). Mosquito Management. Mosquito Information Website. 
http://mosquito.ifas.ufl.edu/

Mosquito_Management.htm (13 May 2008).

Florida State Board of Health. 1965. They must go! (Aedes aegypti). Florida Health Notes 57: 87-102.

Foster WA, Walker ED. 2002. Mosquitoes (Culicidae). In Mullen, G., Durden, L. (Eds.) Medical and Veterinary Entomology (p 203-262). Academic press, Sand Diego, CA. 597 pp.

Gubler, DJ. (1989). Aedes aegypti and Aedes aegypti-borne disease control in the 1990's: Top down or bottom up. Centers for Disease Control. http://wonder.cdc.gov/wonder/prevguid/p0000434/ p0000434.asp (11 April 2008).

Harper JP, Paulson SL. 1994. Reproductive isolation between Florida strains of Aedes aegypti and Aedes albopictus. Journal of the American Mosquito Control Association 10: 88-92.

Integrated Taxonomic Information System. Aedes aegypti (Linnaeus). http://wonder.cdc.gov/wonder/prevguid/p0000434/ p0000434.asp (11 April 2008).

Maricopa County Environmental Services. (2006). Lifecycle and information on Aedes aegypti mosquitoes. Maricopa County, AZ. http://www.maricopa.gov/EnvSvc/VectorControl/ Mosquitos/MosqInfo.aspx (13 May 2008).

Melville RV, Smith JDD. (1987). Official lists and indexes of names and works in zoology. International Committee for Zoological Nomenclature. http://www.iczn.org/names_works_zoology.pdf (13 May 2008).

Nelson MJ. 1986. Aedes aegypti: Biology and Ecology. Pan American Health Organization. Washington, D.C.

Norrby E. 2007. Yellow fever and Max Theiler: the only Nobel Prize for a vaccine. Journal of Experimental Medicine. 204: 2779-2784.

Rey J. (2006). The Mosquito. EDIS. http://edis.ifas.ufl.edu/IN652 (13 May 2008).
Rey J. (2007). What is Dengue?. EDIS. http://edis.ifas.ufl.edu/IN699 (13 May 2008).

Severo OP. 1959. Aedes aegypti eradiation in the Americas. Pan American Sanitary Bureau.

Soper FL. 1965. The 1964 status of Aedes aegypti eradication and yellow fever in the Americas. American Journal of Tropical Medicine and Hygiene 14: 887-891.

Tabachnick WJ. 1991. Evolutionary genetics and arthropod-borne disease: the yellow fever mosquito. American Entomologist 37: 14-24.

Tabachnick WJ, Connelly CR, Smartt CC. (2006). Blood feeding insect series: yellow fever. EDIS. http://edis.ifas.ufl.edu/IN659 (13 May 2008).

Tabachnick WJ, Munstermann LE, Powell JR. 1978. Genetic distinctness of sympatric forms of Aedes aegypti in East Africa. Evolution 33: 287-295. 